\title{
Advancing Liquid Metal Jet Printing
}

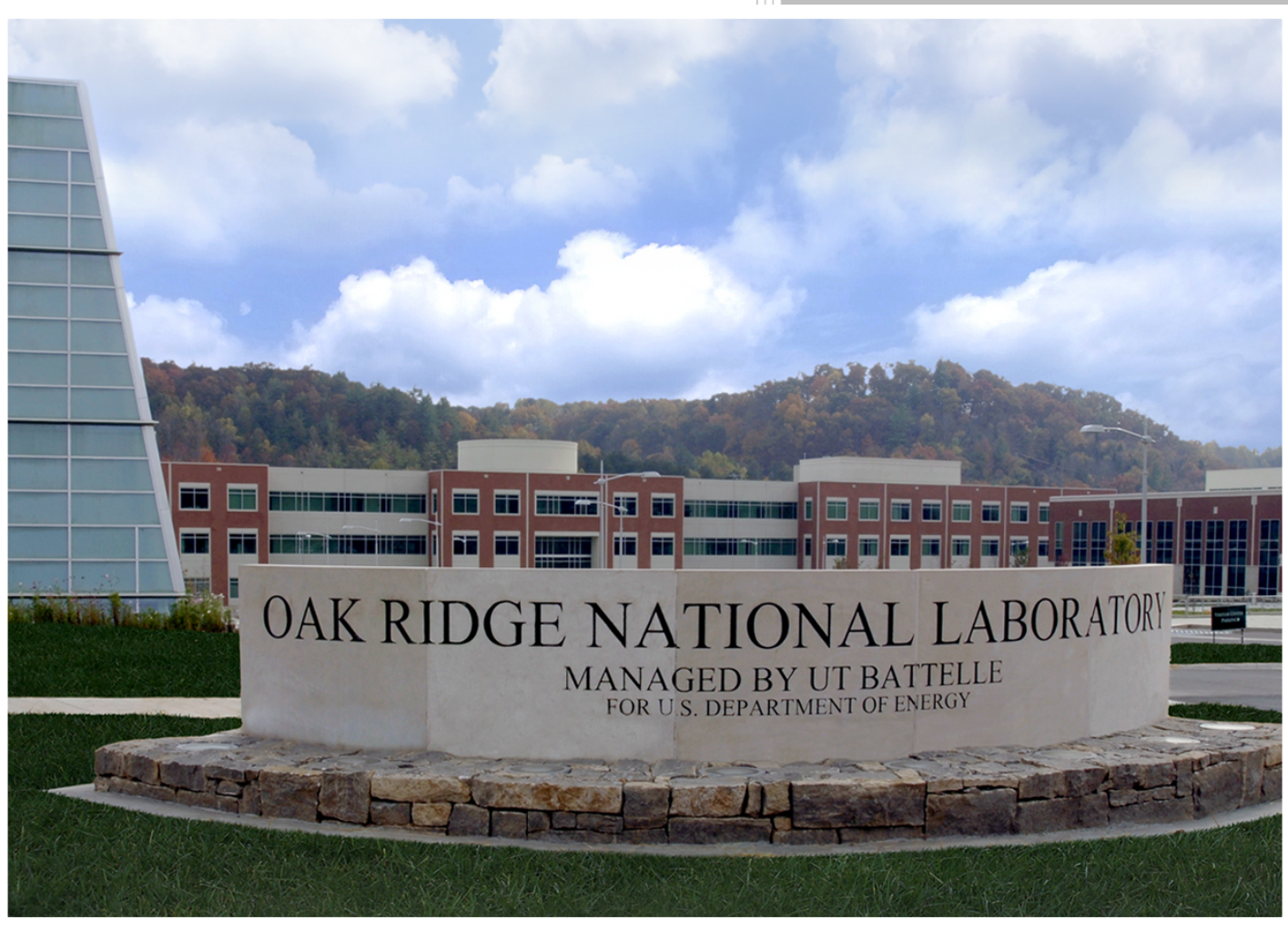

Amy Elliott, PhD

CRADA FINAL REPORT NFE-18-07178

Approved for Public Release. Distribution is Unlimited. 


\section{DOCUMENT AVAILABILITY}

Reports produced after January 1, 1996, are generally available free via US Department of Energy (DOE) SciTech Connect.

Website http://www.osti.gov/scitech/

Reports produced before January 1, 1996, may be purchased by members of the public from the following source:

National Technical Information Service

5285 Port Royal Road

Springfield, VA 22161

Telephone 703-605-6000 (1-800-553-6847)

TDD 703-487-4639

Fax 703-605-6900

E-mail info@ntis.gov

Website http://www.ntis.gov/help/ordermethods.aspx

Reports are available to DOE employees, DOE contractors, Energy Technology Data Exchange representatives, and International Nuclear Information System representatives from the following source:

Office of Scientific and Technical Information

PO Box 62

Oak Ridge, TN 37831

Telephone 865-576-8401

Fax 865-576-5728

E-mail reports@osti.gov

Website http://www.osti.gov/contact.html

This report was prepared as an account of work sponsored by an agency of the United States Government. Neither the United States Government nor any agency thereof, nor any of their employees, makes any warranty, express or implied, or assumes any legal liability or responsibility for the accuracy, completeness, or usefulness of any information, apparatus, product, or process disclosed, or represents that its use would not infringe privately owned rights. Reference herein to any specific commercial product, process, or service by trade name, trademark, manufacturer, or otherwise, does not necessarily constitute or imply its endorsement, recommendation, or favoring by the United States Government or any agency thereof. The views and opinions of authors expressed herein do not necessarily state or reflect those of the United States Government or any agency thereof. 
Energy and Transportation Science

Advanced Manufacturing Office

\title{
ADVANCING LIQUID METAL JET PRINTING
}

\author{
Authors \\ Amy Elliott \\ Amit Shyam \\ Orlando Rios \\ Tom Muth
}

Date Published:

September 30, 2019

\author{
Prepared by \\ OAK RIDGE NATIONAL LABORATORY \\ Oak Ridge, Tennessee 37831-6283 \\ managed by \\ UT-BATTELLE, LLC \\ for the \\ US DEPARTMENT OF ENERGY \\ under contract DE-AC05-00OR22725
}

Approved For Public Release 



\section{CONTENTS}

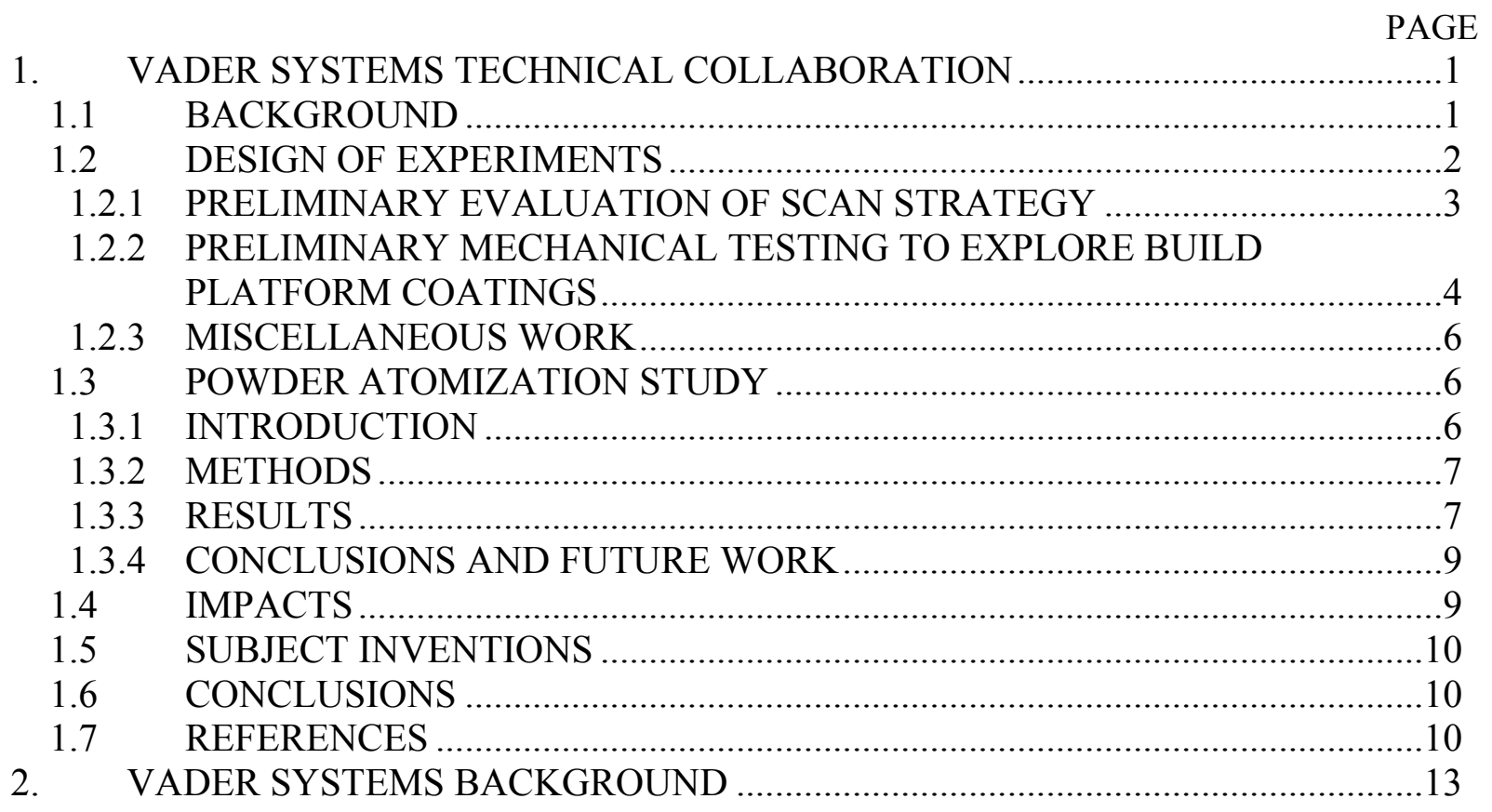




\section{LIST OF FIGURES}

Figure 1. A) Vader Systems platform; B) image of molten aluminum deposition; C) and D) parts

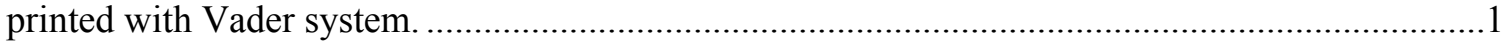

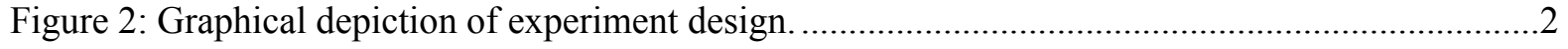

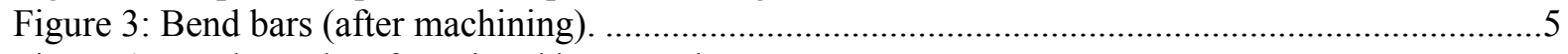

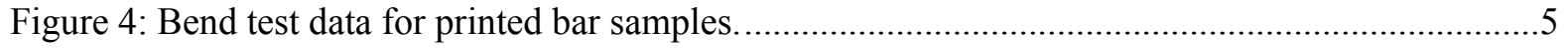

Figure 5: Vader Systems Magnetojet atomization setup................................................................

Figure 6: SEM image of Vader Systems powder.......................................................................

Figure 7: Hypothesis for craters in particles due to impact with other particles during solidification...8

Figure 8: Cross-section of the particles show some pores and evidence of particle collision. ..............8

Figure 9: Vacuum porosity in the powder particles created by solification densification of the powder

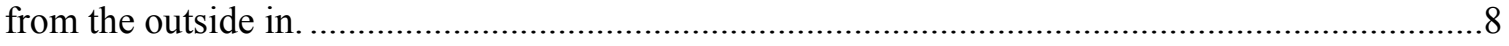

Figure 10: Particle size distribution for Trials 2 and 3 powders measured by Malvern G3SE.............9

Figure 11: Particle circularity for Trials 2 and 3 powders measured by Malvern G3SE...................... 


\section{ACKNOWLEDGEMENTS}

This CRADA NFE-18-07178 was conducted as a Technical Collaboration project within the Oak Ridge National Laboratory (ORNL) Manufacturing Demonstration Facility (MDF) sponsored by the US Department of Energy Advanced Manufacturing Office (CPS Agreement Number 24761).

Opportunities for MDF technical collaborations are listed in the announcement "Manufacturing Demonstration Facility Technology Collaborations for US Manufacturers in Advanced

Manufacturing and Materials Technologies" posted at http://web.ornl.gov/sci/manufacturing/docs/FBO-ORNL-MDF-2013-2.pdf. The goal of technical collaborations is to engage industry partners to participate in short-term, collaborative projects within the Manufacturing Demonstration Facility (MDF) to assess applicability and of new energy efficient manufacturing technologies. Research sponsored by the U.S. Department of Energy, Office of Energy Efficiency and Renewable Energy, Advanced Manufacturing Office, under contract DE-AC0500OR22725 with UT-Battelle, LLC. 


\begin{abstract}
ORNL worked with Vader Systems to investigate their drop-on-demand molten aluminum additive manufacturing system. The investigation involved studying process-property relationships such as speed vs. hardness. Vader produced samples that were characterized by ORNL via CT scanning, hardness mapping, and other techniques.
\end{abstract}

\title{
1. VADER SYSTEMS TECHNICAL COLLABORATION
}

This phase one technical collaboration project (MDF-TC-2018-138) was begun on February 7 , 2018 and was completed on September 30, 2019. The collaboration partner, Vader Systems, is a small business. Results showed that much work needs to be done to ensure fully dense prints, more specifically, that the current toolpath scheme results in high porosity in the part.

\subsection{BACKGROUND}

Vader Systems is a company founded by a father and son team, Scott and Zachary Vader, around the concept of additively manufacturing aluminum geometries using molten metal inkjet deposition. Additive manufacturing (AM) of aluminum has traditionally been unachievable except with laser powder bed fusion, which is a high-cost process. Due to its high potential for oxidation, aluminum is difficult to sinter if used in indirect processes like binder jetting and also difficult to weld in processes like directed energy deposition (Metal BAAM). Therefore, the Vader process fills a huge gap in aluminum AM in terms of low cost production. Figure 1 shows the Vader process and some example parts printed on this low-cost system.

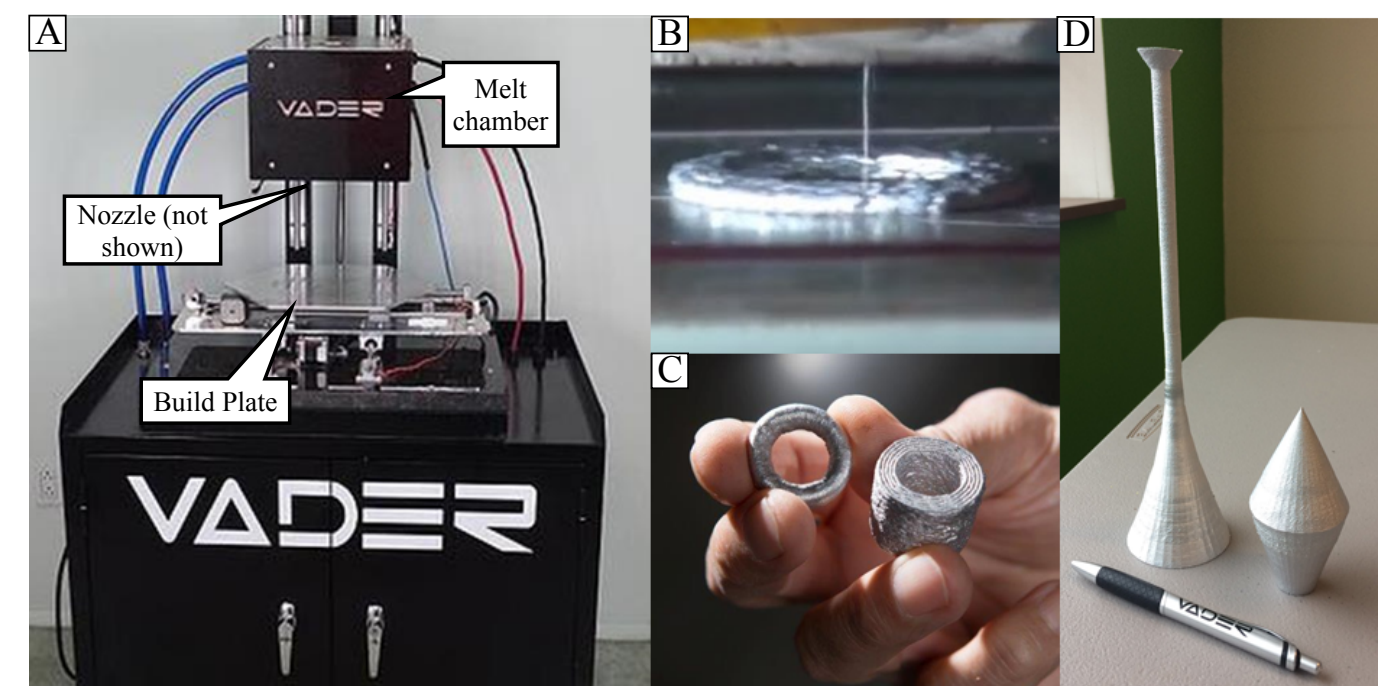

Figure 1. A) Vader Systems platform; B) image of molten aluminum deposition; C) and D) parts printed with Vader system.

The goal of the technical collaboration between Vader Systems and ORNL was to optimize print parameters in the Vader System's MagnetoJet technology by mapping process settings to material properties. The work performed during this project including experimental design and planning, preliminary sample fabrication and analysis, using the molten metal jetting technology. It should be noted that during the course of this Phase 1 work, Vader systems was acquired by Xerox, and for legal reasons the work must be continued under a new CRADA with Xerox. Thus, this report covers the work that was completed toward finishing the Phase 1 objectives, however due to the acquisition 
the project wasn't completed. It is anticipated that once this CRADA is closed a new one will be negotiated.

\subsection{DESIGN OF EXPERIMENTS}

Discuss the technical results here. The total length of this report should be approximately 3-5 pages. Use a data table if available. This report should be completely public and will be posted on OSTI and the ORNL Manufacturing web site. Reference figures as (Fig. 1).

The objective of the research was to understand the effect of process variables on the final properties of parts printed with Vader technology. Process variables of interest include nozzle temperatures, platform temperatures, deposition rate, and drop spacing, and properties of interest include mechanical strength, ductility, and hardness. A taguchi-based design of experiments was created to quantify the variable that has the most affect on certain properties. The Taguchi method uses statistics to reduce the number of experiments needed to understand significant variables in a process. After using the taguchi method, the most significant variables can be studied to find the optimal print parameters. Figure 1 is a graphical depiction of the experiment plan.

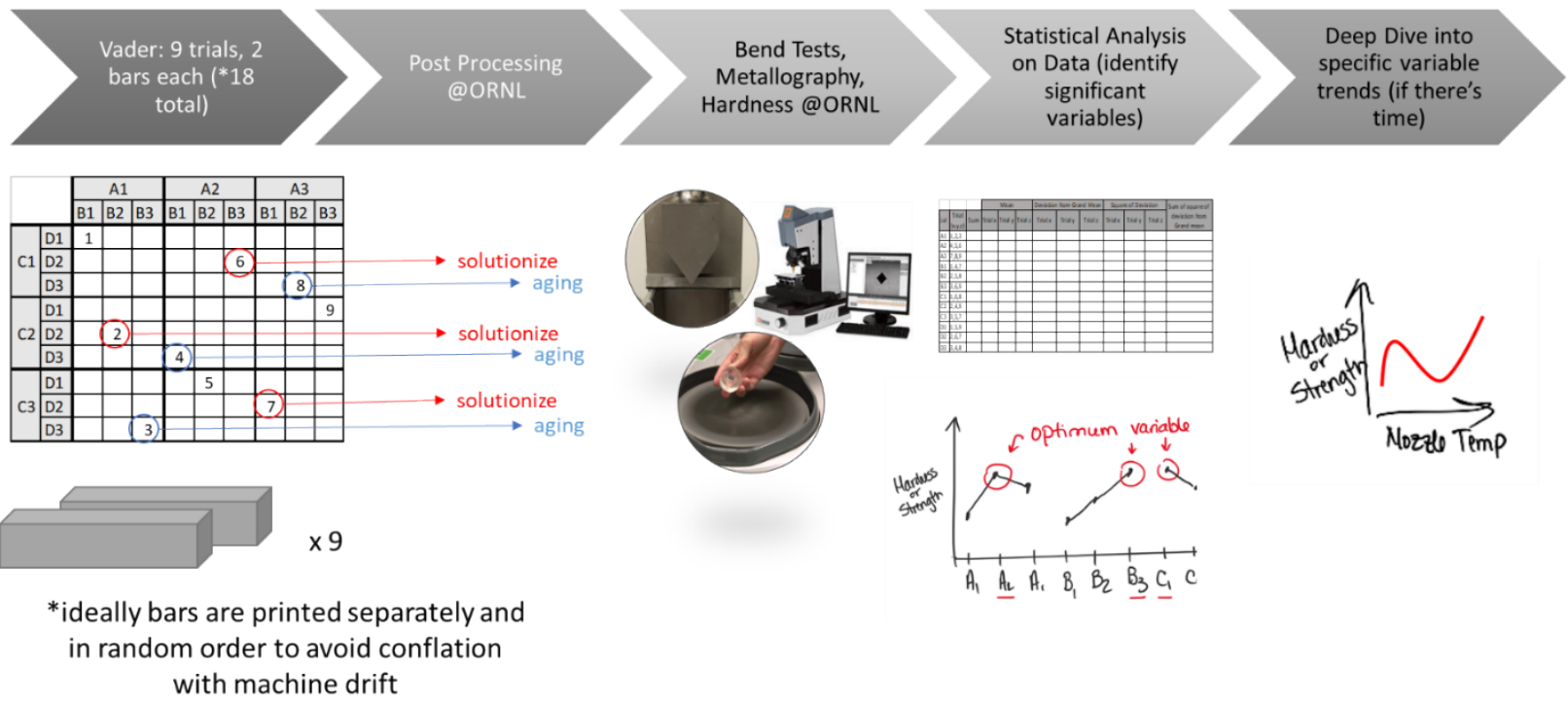

Figure 2: Graphical depiction of experiment design.

Ultimately, the "optimal" print parameters would result in fully dense prints with sufficiently small grain sizes. The grain size of a metal is a major factor in determining mechanical properties, and since post-heat treatments can only be used to grow grains, a smaller grain size from the printing process is desired. Initial microscopy performed outside of ORNL on the Vader printed samples reveal significant annealing (eg large grain sizes), which is undesirable since annealing cannot be reversed (e.g. large grains cannot be made smaller through post-treatments). Thus, a target for the study is to achieve smaller grains. The initial variables selected for the study included nozzle temp, platform temp, and volume deposition rate, and the drop spacing. First, the nozzle temperature is controlled by a heating element wrapped around the ceramic nozzle and was typically at $700 \mathrm{C}$ for Vader's prints. By increasing the temperature of the nozzle and therefore the molten metal droplets, it was thought that either better bonding could take place between the new and already deposited droplets or the microstructure would be affected. Second, the the platform temperature also contributes to the overal thermal energy put into the part as it's printing, which also affects the microstructure and subsequently the mechanical properties. Similarly, the volume deposition rate or the drops per sec also affects the thermal energy in the system - and potentially printing slower would 
prevent grain growth. Finally, the drop spacing was of interest in this study to understand it's affect on the size and shape of grains. Table 1 below lists each of these variables and the experiment settings for the study.

Table 1: Process variable and levels

\begin{tabular}{|c|c|c|c|c|}
\hline Trial & Nozzle Temp $\left({ }^{\circ} \mathrm{C}\right)$ & Platform Temp $\left({ }^{\circ} \mathrm{C}\right)$ & Vol. Rate $\left(\mathrm{mm}^{3} / \mathrm{s}\right)$ & Drop Spacing $(\mathrm{mm})$ \\
\hline 1 & 700 or TBD & 200 & 5 & 0.3 \\
\hline 2 & 700 or TBD & 300 & 10 & 0.4 \\
\hline 3 & 700 or TBD & 400 & 15 & 0.5 \\
\hline 4 & Min +100 & 200 & 10 & 0.5 \\
\hline 5 & Min +100 & 300 & 15 & 0.3 \\
\hline 6 & Min +100 & 400 & 5 & 0.4 \\
\hline 7 & Min +200 & 200 & 15 & 0.4 \\
\hline 8 & Min +200 & 300 & 5 & 0.5 \\
\hline 9 & Min +200 & 400 & 10 & 0.3 \\
\hline
\end{tabular}

\subsubsection{Preliminary Evaluation of Scan Strategy}

Beyond the variables and levels previously listed, scan strategy was also a factor that was considered. Scan strategy refers to the path that the print nozzle takes while creating a layer - which can vary from concentric paths to raster patterns to others. A new scan strategy was being developed by the Vader team that theoretically would solve grain size issues. The Vader team wanted to explore this new scan strategy as a basis for the design of experiments. Thus, some preliminary samples were created for analysis. Two samples sizes were explored: a $5 \mathrm{~mm}$ cube and a $15 \mathrm{~mm}$ cube. The purpose behind the two sizes was that the thermal gradient in a larger part would be more significant and perhaps affect the grain structure.

The samples were analyzed on a X-ray computed tomography (CT) scanner. Unfortunately, initial evaluation of the samples with revealed a significant amount of porosity, revealing that the new scan strategy was flawed in some way. Possibly, the individual droplets were cooling too much between each deposition, and their resulting increased viscosity prevented the droplets from fully penetrated the crevices in the print surface. Further exploration of the phenomena is needed, but overall the large and small printed cubes had similar porosity organized along the layer planes as shown in Table 2 . The profiles of the pore sizes and frequency were built using the instrument's software. The total voxels (volumetric pixel) occupied by the segmented pores/voids is divided by the total number of voxels of the scanned samples, to obtain the \% porosity for each sample. Assuming a spherical pore/void geometry, equivalent diameters are calculated for the segmented pores/voids based on their volumes and presented above with respect to their relative frequency of occurrence. 
Table 2: Preliminary samples to understand scan strategy

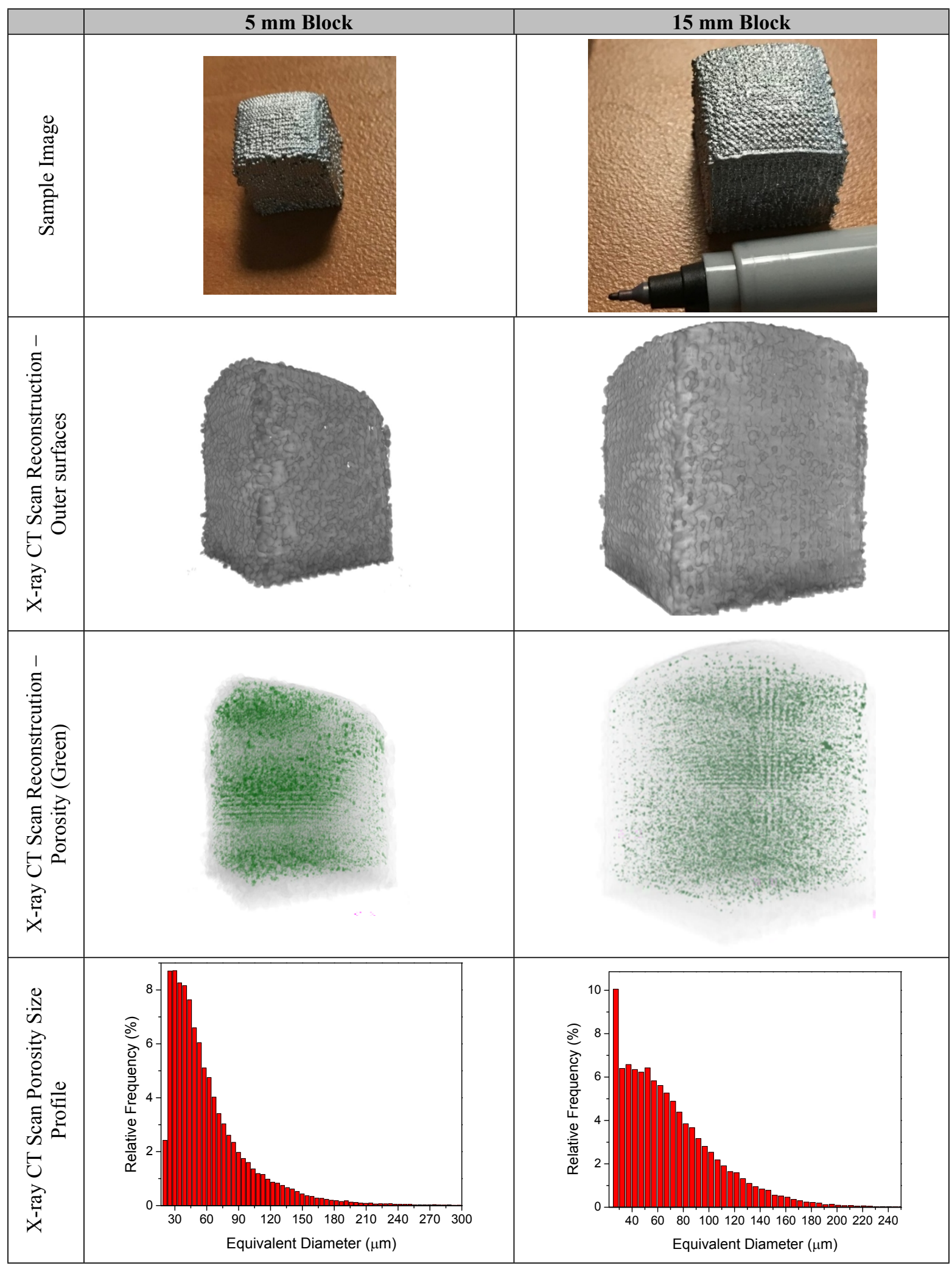

\subsubsection{Preliminary Mechanical Testing to Explore Build Platform Coatings}


Another variable that needed exploration for the design of experiments was build platform coatings. The platform coating is important for part removal after the print is complete. Specifically, the "right" coating can release the part easily from the build plate and avoid extra machining or cutting. Further, the "wrong" coating can release the part too easily and cause delamination during the print. The two coatings explored in this brief study were copper and nickel. These two metals are easily plated onto many metal substrates.

Three bar samples were printed using Vader Systems' MagnetoJet technology varying substrate plating material and deposition speed. The print head temperature was held constant for each sample. The printed geometries were approximately $10 \times 10 \times 60 \mathrm{~mm}$. The bars were machined to remove the printed finish and bent on a 3-point bend test machine.

Table 3: Bend sample print parameters

\begin{tabular}{|c|c|c|c|}
\hline & Sample 1 & Sample 2 & Sample 3 \\
\hline Print Speed & $15 \mathrm{~mm}^{3} / \mathrm{s}$ & $15 \mathrm{~mm}^{3} / \mathrm{s}$ & $21 \mathrm{~mm}^{3} / \mathrm{s}$ \\
\hline Build Surface Plating & Copper & Nickel & Copper \\
\hline
\end{tabular}

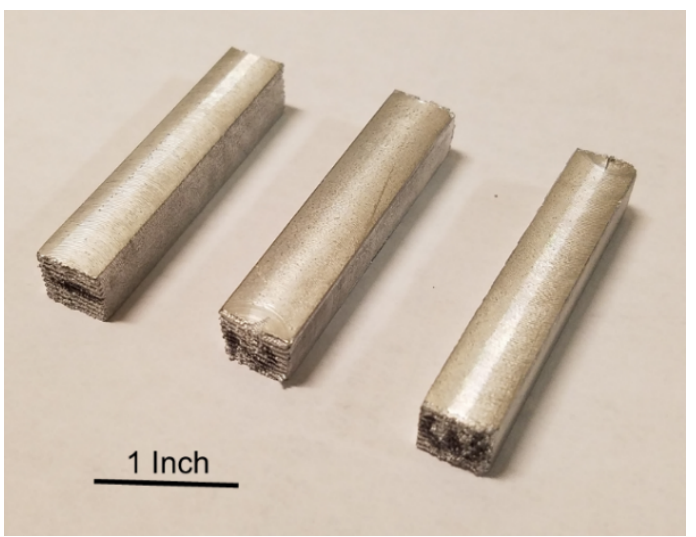

Figure 3: Bend bars (after machining).

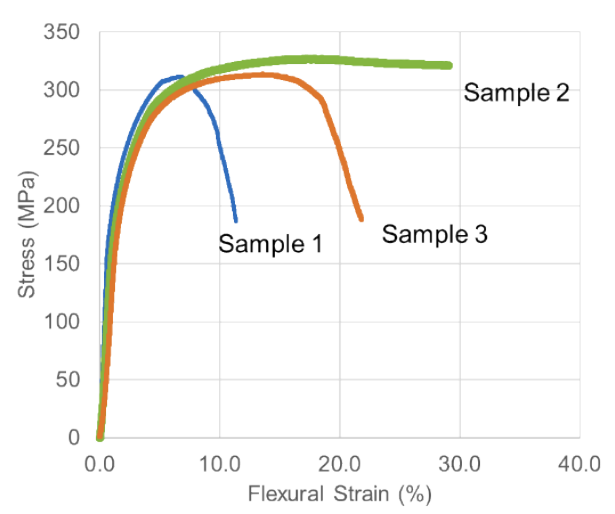

Figure 4: Bend test data for printed bar samples.

Bend test results show a slight difference in max stress but major difference in elongation/ductility between the 3 samples. Sample 1 had the lowest strain around 12\%, Sample 2 had the highest strain rate around $30 \%$, and Sample 3 had a strain rate in the middle of the other two samples, around 23. Higher ductility is linked to increased annealing which is linked to the temperature of the part, and as mentioned previously, a highly annealed metal is undesirable. The sample with the highest strain and therefore ductility was the one produced with slower print speed with nickel plating (Sample 1). When print speed was held the same, the sample printed on the nickelcoated substrate (Sample 2) still had significantly higher ductility than the sample printed on the copper substrate (Sample 1). Thus, it can be surmised that the print substrate and print speed can have significant effect on material properties.

Intuitively, the more conductivity between the substrate and the part would allow more thermal energy to enter the part and induce more annealing. Thus, more thermal energy is trapped in a sample that is insulated from the build plate, which means the sample printed on the nickel coating (less conductive) was probably at a higher temperature than the sample printed on the copper substrate (more conductive). Further, the sample with highest rate of heat transfer into the part was sample 3, which was printed a volumetric rate $40 \%$ higher than the other samples. Thus, the increase of thermal energy entering sample 3 most likely made that sample reach a much higher temperature than the other two samples, despite being printed on a copper substrate. Unfortunately, the temperatures of the sample were not measured during this study as the heat transfer effects of the nozzle and print bed were not well understood at that time. Temperature measurement along with heat transfer modelling will need to be conducted to fully explain the effects of these variables, however, it is clear that the 
key to control annealing in the Vader process is the heat transfer rates between the print head (dictated by print temperature and speed) and the heat transfer rate between the part and the build plate (dictated by the coating and the build plate temperature). More concisely, lowering print speeds and print temperatures will reduce the rate thermal energy enters the part, and lowering the build plate temperature and using a conductive coating will increase the rate that thermal energy exits the part. Together, reducing the reduced thermal energy in the part will reduce the part temperature and ultimately avoid unwanted annealing.

Future microstructural analysis should quantify the grain sizes and therefore the extent of the annealing each sample. Also, hardness testing should be conducted to confirm the ductility data. Finally, modelling should be started to understand heat transfer and resulting retained thermal energy in each part. Factors to consider are droplet temperature, droplet deposition speed, increased mass as part grows, thermal capacity of the part, conductivity and contact area between part and substrate, surface area of the part, print chamber temperature, etc.

\subsection{POWDER ATOMIZATION STUDY}

\subsubsection{Introduction}

Powder Metal (PM) production serves the metal injection molding (MIM), pressing and sintering, hot-isostatic pressing, and now the Additive Manufacturing (AM) industries [1][2]. PM production occurs through the atomization process, a process of melting metal feedstock, breaking that molten material into small drops, and cooling the molten drops to form discrete powder particles. The powder is then sieved to the desired particle size distribution. PM production is most commonly performed with atomization processes such as liquid atomization, gas atomization, and plasma or centrifugal atomization [3].

Liquid and gas atomization work by breaking up a stream of molten metal and allowing the resulting metal droplets to cool and solidify before impacting a collection chamber below. Liquid atomization utilizes a high-velocity spray of water, oil, or other liquid to break the stream of molten metal into drops, cooling them instantly to form highly irregular particles [3]. Because of the contact of the water against the molten metal, the metal typically reacts with the oxygen in the water and the powder is oxidized [4][5][6]. Gas atomization works by spraying inert gas into a stream of molten material, however since the gas does not instantly cool the molten droplets, they are allowed to coalesce into spherical droplets and solidify, forming more spherical particles. Because of the turbulence of the process, the sprayed gas can get trapped in the particles and manifest themselves as defects in the final part [7][8].

Plasma atomization works by spinning a solid stock of metal and arcing a current through the end to induce melting. The high-speed rotation of the stock material flings droplets of the molten material in a direction tangential to the rotation, separating them from the main stock piece and creating discrete droplets [3]. While plasma atomization produces the highest quality particles in terms of sphericity, composition, and porosity among the three discussed, the particle diameters are still not as highly controlled as needed for AM.

Electron beam melting is an AM process that utilizes a powder bed and an electron beam to build parts by repeatedly spreading layers of powder and welding them with an electron beam. Previous work has shown that the quality of the powder feedstock is directly correlated to the porosity of the final part. High porosity in an AM part constitutes areas of potential failure in the structure of the part and are highly undesirable. For electron beam, it was found that the higher the sphericity and the lower the porosity of the starting powder feedstock[9], [10]. Furthermore, it has been estimated/found that the narrower the PSD, the more uniform the melting behavior of the powder bed and the more predictable the EBeam process is in terms of melt solidification, grain structure, and porosity.

Magnetojet (MJ) technology was invented by Zack Vader in 2011 as a low cost additive manufacturing process for creating aluminum parts [11].The MJ process works on similar principles to inkjet: a fluid feedstock is fed into a small chamber, a pulse of pressure is created in the chamber, 
and the molten material is forced out of the chamber through a small nozzle to form a long and narrow column of molten material with some velocity (reference IBM papers from the 80's). Once the column of material reaches a sufficient length, the surface tension of the fluid induces a break between the column and the nozzle, and the column collapses into a sphere (the lowest-energy state). With the MJ process, pulsed magnetic and electrical induction through the molten aluminum produces a Lorentz force, which ultimately forces the molten aluminum through the nozzle in discrete pulses.

Just like with inkjet droplet formation, the advantage of the MJ process is the uniformity of the droplets and extent to which the droplet characteristics can be controlled with the input waveform. Current results show the formation of highly uniform powders with high sphericity and narrow PSD, unparalleled by traditional PM production. This work describes powder production trials with the MJ process and characterization of the powder via scanning electron microscopy (SEM), laser particle size analysis, optical particle analysis, and cross-sectioning via traditional metallography techniques.

\subsubsection{Methods}

A Malvern Morphologi G3SE powder imaging system was used on each batch of MJ powder. The Malvern samples were prepared by collecting a small amount of powder with a micro spatula and inserting them into the dispersion chamber. The powder is then dispersed via a pulse of pressurized Argon, and the particles fall evenly and settle across a large, backlit, glass slide. The microscope scans the area of the slide imaging the entire area. The software identifies the profiles of individual particles and

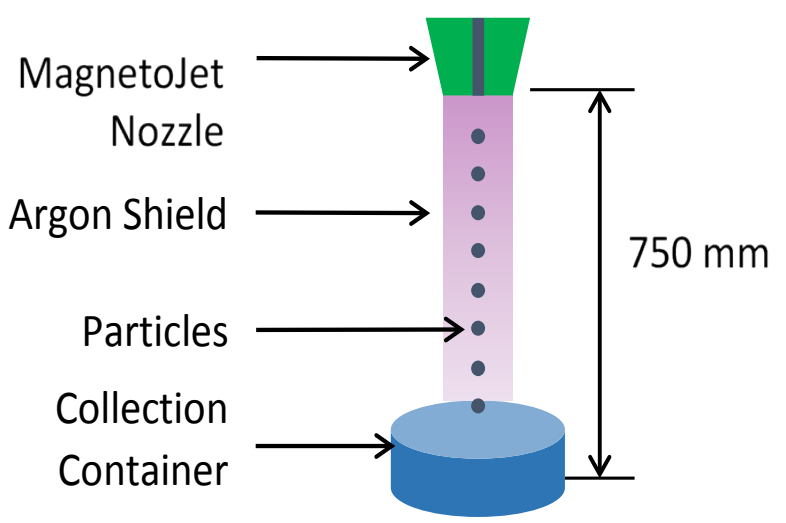

Figure 5: Vader Systems Magnetojet atomization setup. extracts each particle image. Finally, the particle images are adjusted for contrast and their pixels are measured for area, maximum distance, and other parameters. The pixel data is then used to calculate particle circle equivalent (CE) diameters, circularity, and other properties. Finally, to characterize porosity of the particles, the powders were mounted and cross-sectioned via standard metallography techniques and imaged via optical and SEM microscopy.

\subsubsection{Results}

The powder production yielded near $100 \%$ efficiency in that very few powder particles were outside the average size. SEM images revealed spherical powders with highly uniform diameters. It was observed that nearly all of the powder particles had 1-2 visible indentations on one side ranging from 20-40 $\mu \mathrm{m}$ in diameter (Figure 6). It is hypothesized that this is due to the particles colliding with each other in the collection container as shown in Figure 7. Figure 8 is an optical image of crosssectioned powder where darker regions can be seen in the epoxy mount. These circular, darker regions are most likely from particles that lifted during polishing, and since some of these particles overlap with others, these particles must have been partially fused or entangled prior to polishing. Future trials should be conducted with a much longer fall time to allow the droplets to cool and harden sufficiently before impact with the collection container.

Further analysis of the images of particle cross sections revealed some porosity in the particles as shown in Figure Figure 8 and Figure 9. The porosity in Figure 9 is most likely due to gas being trapped during droplet formation, however the porosity in Figure Figure 8 is indicative of vacuum 
pockets formed during the solidification and subsequent densification of the material from the outside in. In other words, the porosity in Figure 9 is caused by the fact that the material decreases in volume as it solidifies, and the hard shell that forms on the outside prevents the particle from shrinking as it cools, creating a vacuum pocket in the center.

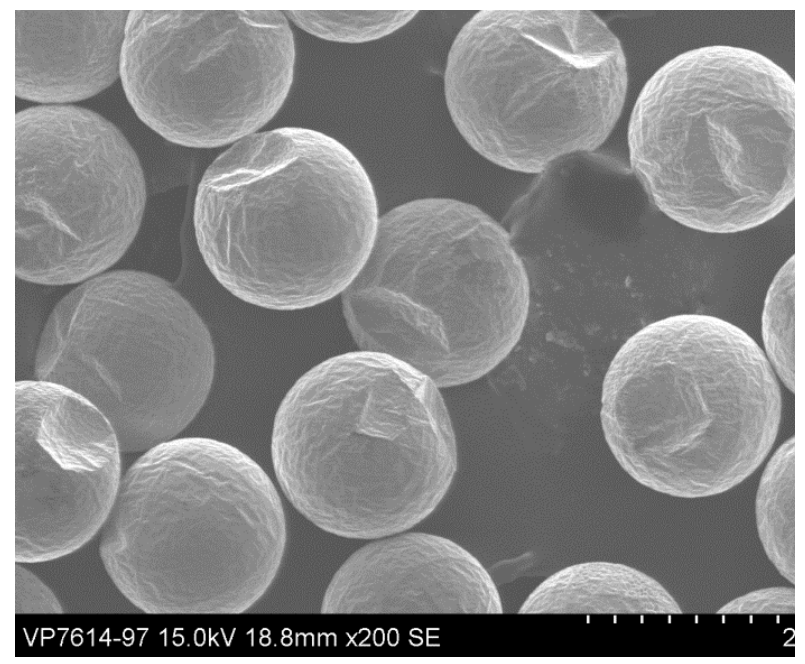

Figure 6: SEM image of Vader Systems powder.

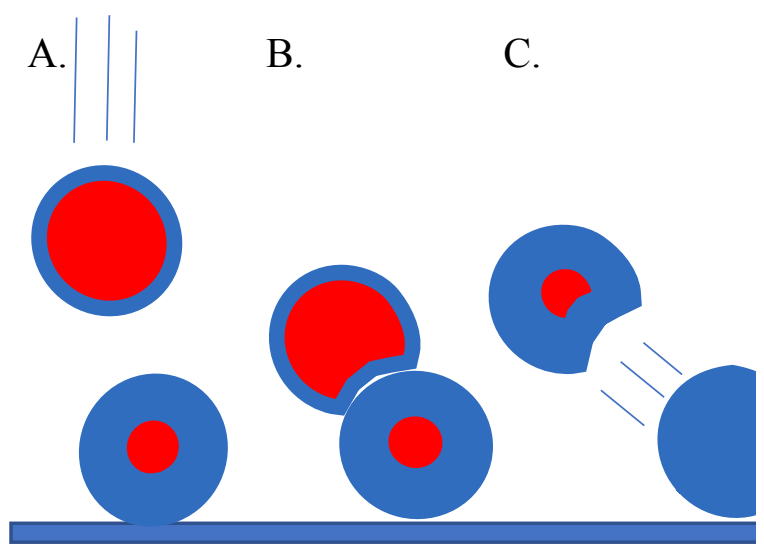

Figure 7: Hypothesis for craters in particles due to impact with other particles during solidification. Red color signifies molten material while the blue signifies solid material. The semisolidified particles collide (A). The more solid lower particle maintains geometry while the newer, more liquid particle above deforms to its the surface(B). The final particles have indentations on one or more sides (C).

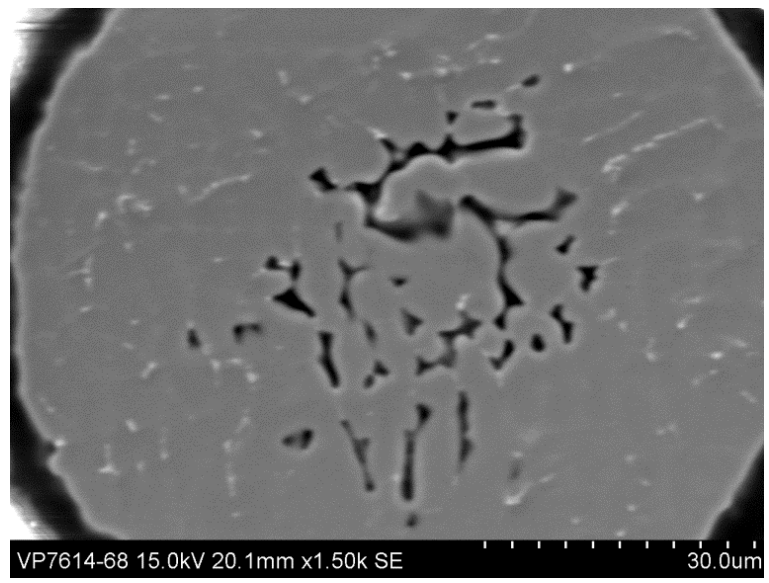

Figure 9: Vacuum porosity in the powder particles created by solification densification of the powder from the outside in.

Optical particle analysis revealed that the diameters of Trial 2 and Trial 3 powders were $165 \mu \mathrm{m}$ and $167 \mu \mathrm{m}$, respectively, showing high consistency in the process between batches. The standard deviations for Trial 2 and Trial 3 powders were $17.65 \mu \mathrm{m}$ and $19.32 \mu \mathrm{m}$ respectively, meaning the PSD was exceptionally narrow. The increase in average particle size between Trials 2 and 3 was most likely due to the increase in pulse width from $45 \mu$ s to $46 \mu$ s. Increasing the pulse width means 
increasing the time that the magnetic pulse is active, which would increase the amount of material flowing through the nozzle with each pulse and therefore the final droplet and particle size. Thus, pulse width is most likely the main parameter that affects particle size for a given nozzle. A plot of the PSD is shown in Figure 10.

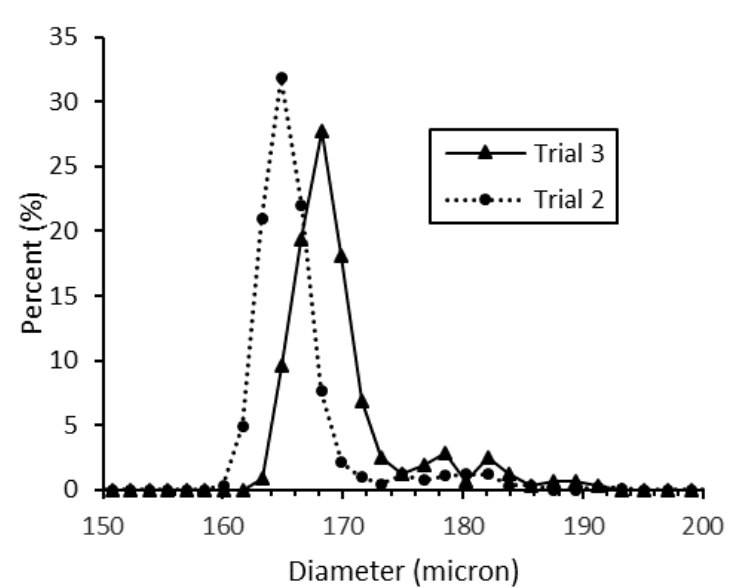

Figure 10: Particle size distribution for Trials 2 and 3 powders measured by Malvern G3SE.

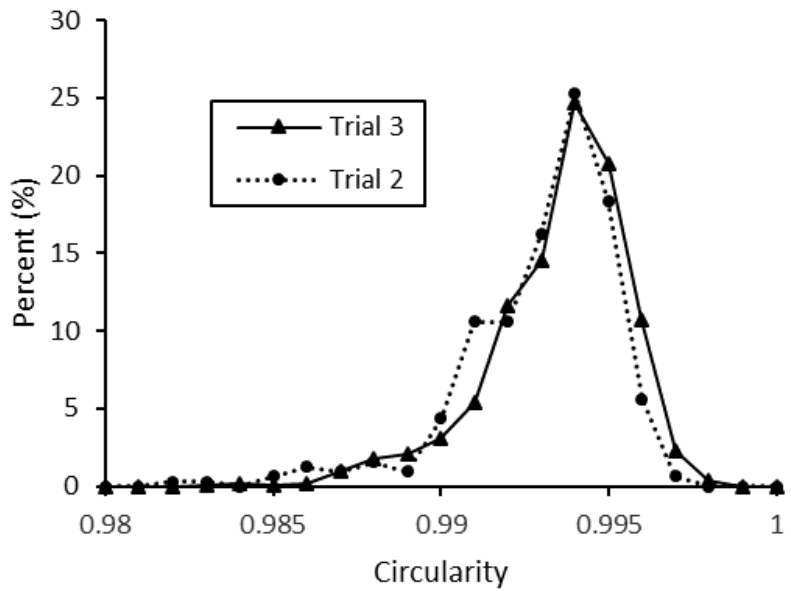

Figure 11: Particle circularity for Trials 2 and 3 powders measured by Malvern G3SE.

Despite deformation due to particle collision, the optical particle analysis revealed average circularity for the powders from Trials 2 and 3 to be 0.987 and 0.985 with a standard deviation of 0.011 and 0.015 , respectively. These values for circularity are exceptionally high for metal powders. A plot of circularity for the powders is shown in Figure 11. The slight deviation in circularity in Trial 2 could be due to error in the device. Overall, the powder produced in this initial study of MJ powder production had high circularity and narrow PSD.

\subsubsection{Conclusions and Future Work}

Aluminum powder was produced with MagnetoJet technology at a rates of .257 and $.322 \mathrm{lbs}$ per hour and analyzed for particle size, shape, and porosity. The two batches of powder had circularities of 0.987 and 0.985 , standard deviation in CE diameter of $17.65 \mu \mathrm{m}$ and $19.32 \mu \mathrm{m}$, and some porosity. Overall, the production of highly uniform and spherical powder via MJ has demonstrated the technology as a viable option for the future of specialty powder production. Future work will include a creating a longer fall time of the particles by either reducing their velocity or increasing the distance between the nozzle and the collection container to prevent disfiguration of the particles from collision prior to solidification.

\subsection{IMPACTS}

This work serves to advance a new AM technology that promises high throughput production of aluminum artifacts. Being able to print aluminum at high speed will serve many industries, including aerospace and even the tooling industry. Further, the low-cost nature of the process means that metal AM could be at the fingertips of small businesses and major manufacturers alike. Plans for moving forward in marketing this technology are definite as Xerox has acquired Vader systems and is investing heavily in the technologies advancement. Continuing this partnership through a new CRADA is strategic for the MDF and AMO. 


\subsection{SUBJECT INVENTIONS}

NA

\subsection{CONCLUSIONS}

Although Vader Systems was acquired during this Phase 1 tech collab and research had to cease, some important information about the density of the parts was discovered and found valuable by the Vader team. Further, the discovery of the link between build plat conductivity, temperature, and other process parameters and the extent of potential annealing was revealed.

The next steps for this collaboration is to start a new CRADA under Xerox and continue characterizing process-property relationships for the purpose of producing the desired properties of the printed aluminum.

\subsection{REFERENCES}

[1] L. F. Pease and W. G. West, Fundamentals of powder metallurgy. Princeton, N.J.: Metal Powder Industries Federation, 2002.

[2] R. M. German, Powder metallurgy and particulate materals processing : the processes, materials, products, properties and applications. Princeton, N.J.: Metal Powder Industries Federation, 2005.

[3] A. Lawley, Atomization : the production of metal powders. Princeton, NJ: Metal Powder Industries Fed., 2003.

[4] I. Nyborg, T. Tunberg, and P. X. Wang, "Surface product formation during water atomization and sintering of austenitic stainless steel powder," Met. Powder Rep., vol. 45, no. 11 , pp. $750-753$, Nov. 1990.

[5] J. F. Watkinson, "Atomization of metal and alloy powders," Powder Metall., vol. 1, no. 1-2, pp. 13-23, Mar. 1958.

[6] D. Chasoglou, E. Hryha, M. Norell, and L. Nyborg, "Characterization of surface oxides on water-atomized steel powder by XPS/AES depth profiling and nano-scale lateral surface analysis," Appl. Surf. Sci., vol. 268, no. Supplement C, pp. 496-506, 2013.

[7] W. Sames, "Additive Manufacturing of Inconel 718 using Electron Beam Melting: Processing, Post-Processing, \& Mechanical Properties," Texas A\&M, 2015.

[8] W. J. Sames, F. Medina, W. H. Peter, S. S. Babu, and R. R. Dehoff, "Effect of process control and powder quality on Inconel 718 produced using electron beam melting," in 8th International Symposium on Superalloy 718 and Derivatives, 2014, pp. 373-387.

[9] W. J. Sames et al., "Effect of process control and powder quality on Inconel 718 produced using electron beam melting," in 8th International Symposium on Superalloy 718 and Derivatives, 2014, pp. 373-387.

[10] H. Miyanaji, M. Orth, J. M. Akbar, and L. Yang, "Process development for green part printing using binder jetting additive manufacturing," Frontiers of Mechanical Engineering, vol. 13, no. 4. pp. 504-512, 2018.

[11] I. H. Karampelas et al., "Drop-on-Demand 3D Metal Printing," in Informatics, Electronics and Microsystems, TechConnect, 2017, pp. 153-155. 


\section{VADER SYSTEMS BACKGROUND}

Vader Systems was founded in 2013. They developed and patented metal 3D printing technology referred to as Magnet-o-Jet. This additive technology was first seen at IMTS in 2016 and was officially launched at RAPID + TCT in 2018. In February of 2019, Xerox announced that they had acquired Vader and their liquid metal 3D printing technology. Xerox has a long history in the printing industry and are focusing on innovation for the future. Xerox currently has 18,000+ active patents, is number 318 on the Fortune 500 list, and has locations in 160 countries around the globe. 